\title{
Erratum to: Localization of Fatty Acyl and Double Bond Positions in Phosphatidylcholines Using a Dual Stage CID Fragmentation Coupled with Ion Mobility Mass Spectrometry
}

Jose Castro-Perez, ${ }^{1,2}$ Thomas P. Roddy, ${ }^{1}$ Nico M. M. Nibbering, ${ }^{4}$ Vinit Shah, ${ }^{1}$ David G. McLaren, ${ }^{1}$ Stephen Previs, ${ }^{1}$ Athula B. Attygalle, ${ }^{5}$ Kithsiri Herath, ${ }^{1}$ Zhu Chen, ${ }^{1}$ Sheng-Ping Wang, ${ }^{1}$ Lyndon Mitnaul, ${ }^{1}$ Brian K. Hubbard, ${ }^{1}$ Rob J. Vreeken, ${ }^{2,3}$ Douglas G. Johns, ${ }^{1}$ Thomas Hankemeier ${ }^{2,3}$

${ }^{1}$ Department of Atherosclerosis Exploratory Biomarkers, Merck Research Laboratories, 126 E. Lincoln Ave, 80Y-2D7, Rahway, NJ 07065, USA

${ }^{2}$ Division of Analytical Biosciences, LACDR, Leiden University, Leiden, The Netherlands

${ }^{3}$ Netherlands Metabolomics Centre, LACDR, Leiden University, Leiden, The Netherlands

${ }^{4}$ LaserLab Amsterdam and Chemistry Department, Vrije Universiteit, Amsterdam, The Netherlands

${ }^{5}$ Center for Mass Spectrometry, Department of Chemistry, Chemical Biology and Biomedical Engineering,

Stevens Institute of Technology, Hoboken, NJ, USA

Erratum to: J. Am. Soc. Mass Spectrom

DOI 10.1007/s13361-011-0172-2

The caption and original version of Fig. 3 were 1 incorrect; the corrected figure and caption are reproduced here. The authors regret the error.

The original version of this article can be found at http://dx.doi.org/10.1007/ s13361-011-0172-2.

Correspondence to: Jose Castro-Perez; e-mail: jose_castro-perez@merck.com 


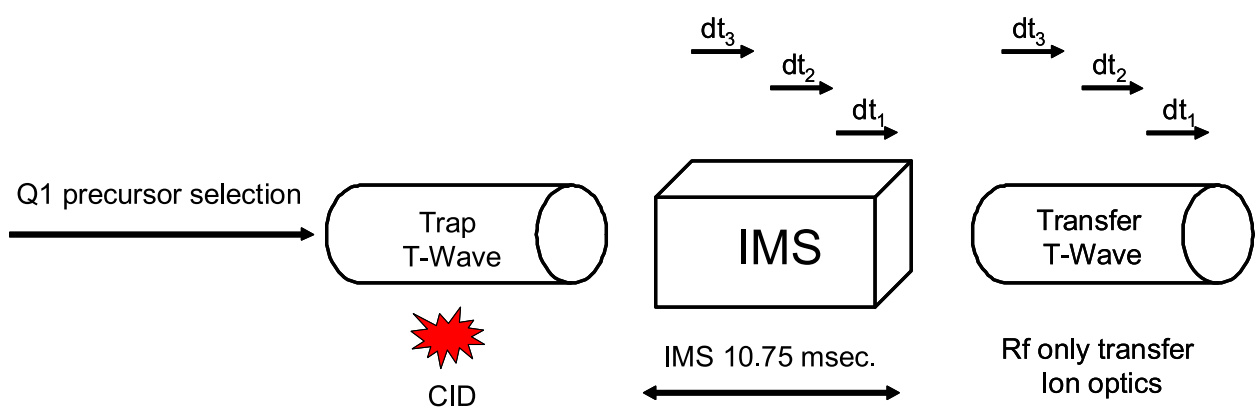

(A)

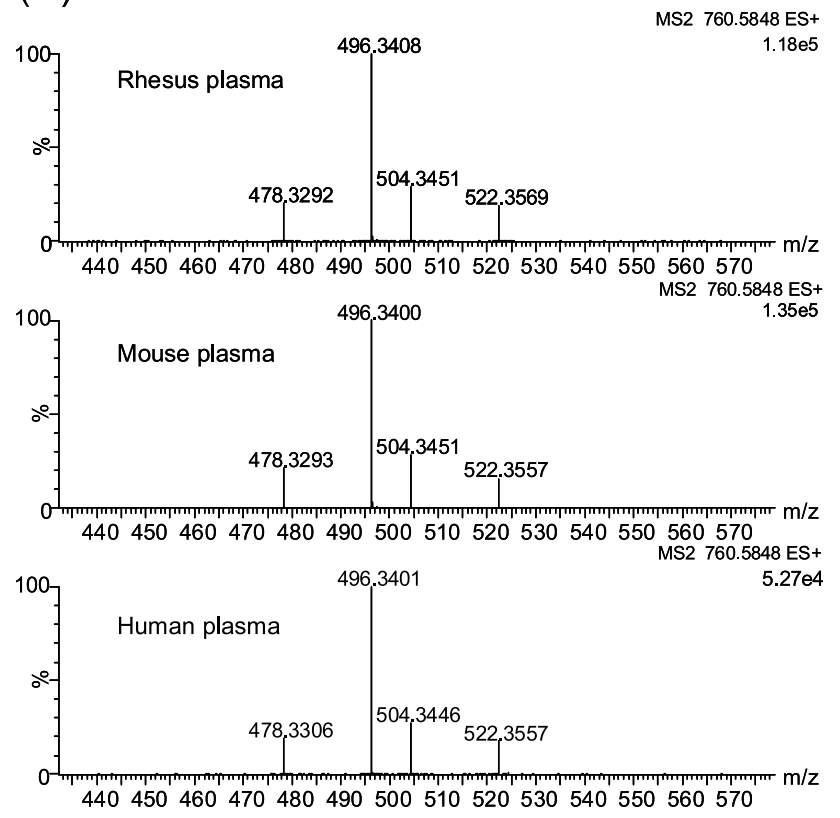

(B)
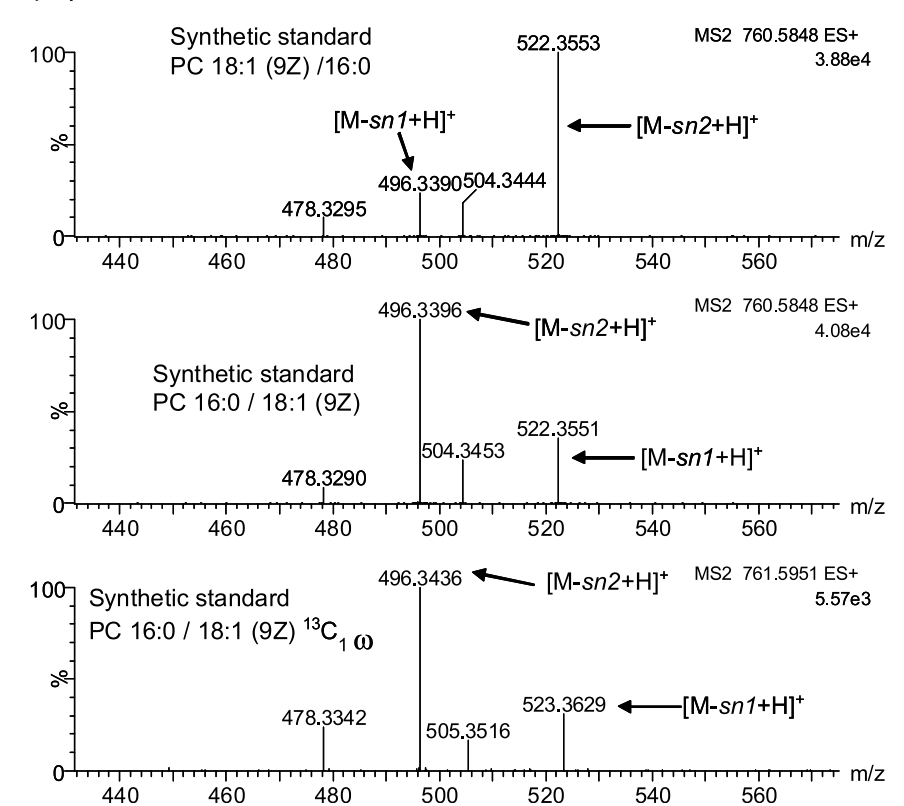

Figure 3. Localization of fatty acyl substitutent in phosphatidylcholines; PC 16:0/18:1 (9Z) fragmentation was conducted by selecting the ion at $m / z 760.5$ in the quadrupole region Q1 followed by collision-induced fragmentation in the trap region. (A) Shows the $m / z$ 430-580 region of collision-induced dissociation mass spectra for drift time regions 2 and 3 for rhesus (upper panel), mouse (mid panel), and human plasma (lower panel) samples by LC-IMS/TOF. (B) Depicts the fragmentation pattern for synthetic standards PC 18:1 (9Z) / 16:0 (upper panel), PC 16:0 / 18:1 (9Z) (mid panel), and PC 16:0/18:1 (9Z) $\left({ }^{13} \mathrm{C}_{1}\right.$ in $\omega$ methyl position) (lower panel) in drift time regions 2 and 3 by flow injection analysis. $\mathrm{dt}=\mathrm{drift}$ time for fragment ions generated in the trap region 